\title{
BELOW-LINER GEOPHYSICAL MONITORING AT A LANDFILL SITE IN THE UK
}

\author{
S B Taylor, R D Barker, \\ The University of Birmingham, \\ Edgbaston, Birmingham, B15 2TT. UK \\ C C White \\ Aspinwall and Co., Walford Manor, \\ Baschurch, Shrewsbury, SY4 2HH. UK
}

\section{INTRODUCTION}

The UK's first electrical monitoring system to be permanently installed below the geomembrane liner of a landfill site has now been operational for two years. The system, developed jointly by Aspinwall and Company, the University of Birmingham and Campus Geophysical Instruments, is installed at a site operated by Cleanaway Ltd and consists of a basic $20 \mathrm{~m}$ grid of electrodes emplaced below a $0.3 \mathrm{~m}$ layer of Bentonite enriched sand (BES), underlying a $2.5 \mathrm{~mm}$ thick HDPE geomembrane liner. Similar systems have been developed and used in the United States (e.g. Van et. al., 1991), and elsewhere in Europe (e.g. Frangos, 1994).

The system is used to carry out regular monitoring at the landfill site in two ways. Firstly, the integrity of the geomembrane liner is monitored. Prior to completion of each phase of the landfill any defects in the liner caused during its installation can be detected, located and repaired. Once installation is complete the system is used to detect future breaks in the liner, should any occur.

Secondly, the sub-liner electrical monitoring system is employed to monitor temporal changes in the subsurface distribution of resistivity. In the event of a leachate leak from the site, departures in the measured and model resistivity distributions from expected background levels will enable mapping and monitoring of any pollution plume formed, thus providing an early warning system on which to plan suitable remedial measures.

\section{SYSTEM DESIGN AND MONITORING PROCEDURE}

The first phase of the monitoring system (White et. al., 1996) consists of 168 high quality 316 stainless steel electrodes each of which is automatically addressable. The data collection is computer-controlled, thereby allowing flexibility in the types of array that can be employed for data collection.

For leak detection, a $1 \mathrm{~Hz}$ current is injected above the liner using an electrode located in the waste material with a return electrode located remotely outside the lined area. The potential is measured at each electrode in the grid and compared to that measured at a second electrode located remotely from the grid and the potential difference normalised by the injected current. To improve on the estimated positions of any leaks that may be present, the normalised 
potential difference measurements are then entered into a parameter optimisation subroutine.

\section{ELECTRICAL POTENTIAL DISTRIBUTION DUE TO A LEAK}

Parra (1988) determined the potential distribution above the liner for a leak located in the geomembrane liner for a simple three-layer system. The potential distribution below the liner for such a system can be determined in a similar fashion. However, as the resistance of the liner material is very high, it behaves as an electrical insulator and the potential distribution due to a leak approximates to that due to a current source, $I$, on the surface of half-space of resistivity $\rho_{s}$. The potential at a distance $\mathrm{r}$ from the leak is simply

$$
\phi(r)=\frac{I \rho_{5}}{2 \pi r} .
$$

In physical terms, water leaking through the hole forms conducting paths along which current can flow. The resulting high current density in the vicinity of the hole produces the localised increase in the potential which characterises the leak response.

\section{MODEL RESULTS}

Using the simple model of a leak source indicated above and a sampling grid similar to that installed at the landfill site, the capabilities of the under-liner monitoring system and the effectiveness of the parameter optimisation procedure have been investigated. Figure la shows the contoured normalised potential difference, in Volts/Amp (V/A), for a single leak located at $(55,15)$ with $5 \%$ added Gaussian noise. The resulting anomaly is spread over a number of points in the grid with the centre forming a broad peak across two of the grid points. It can be inferred from the anomaly that the source is located somewhere between these two grid points. To improve this estimation of the position of the leak, groups of twelve data points are entered into a parameter optimisation procedure. Figure $1 \mathrm{~b}$ displays the contoured normalised potential difference calculated from the weighted average of the optimised fits to three groups of data. Figure lc shows the percentage difference between the model and the fitted values.

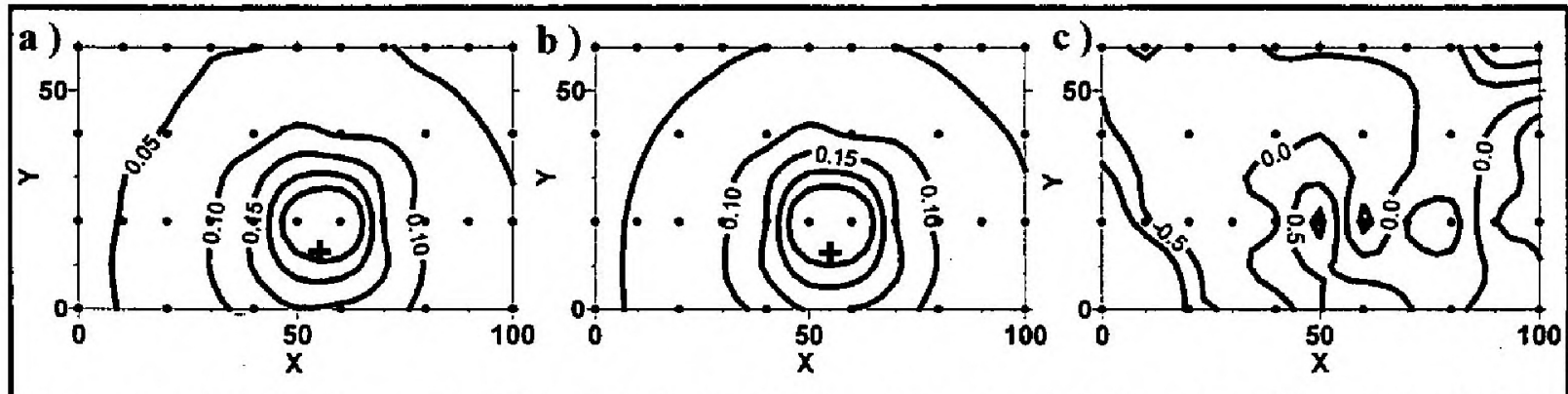

Figure 1 a) Model Normalised Potential Distribution for a single leak at $(55,15)$, b) Optimised Fit to Model c) Percentage Difference Map. - Indicates grid point, + Indicates leak position

\begin{tabular}{|c|c|c|c|}
\hline \multicolumn{2}{|c|}{ Location } & $95 \%$ Confidence & $68 \%$ Confidence \\
\hline $\mathrm{X}$ & 55.1 & \pm 0.4 & \pm 0.2 \\
$\mathrm{Y}$ & 14.9 & \pm 0.5 & \pm 0.2 \\
\hline $\mathrm{X}$ & 55.0 & \pm 0.3 & \pm 0.1 \\
$\mathrm{Y}$ & 15.0 & \pm 0.4 & \pm 0.2 \\
\hline $\mathrm{X}$ & 55.1 & \pm 0.3 & \pm 0.2 \\
$\mathrm{Y}$ & 15.0 & \pm 0.5 & \pm 0.2 \\
\hline
\end{tabular}

Table 1: Predicted Leak Location from Optimised Fitting to three Groups of Data 
The estimated location of the leak and the associated confidence limits for these parameters as predicted by the optimisation procedure are given in Table 1. It is clear from the results that there is very good agreement between the predicted and true location of the leak.

\section{REAL DATA EXAMPLE}

A number of leaks have been detected using the sub-liner grid of electrodes, examples of which were presented in Taylor et. al. (1996). From the contour plots of the measured normalised potential difference data, the position of a leak can only be predicted to within a $20 \mathrm{~m} \times 20 \mathrm{~m}$ grid square. The leak is then accurately located using an above-liner manual leak

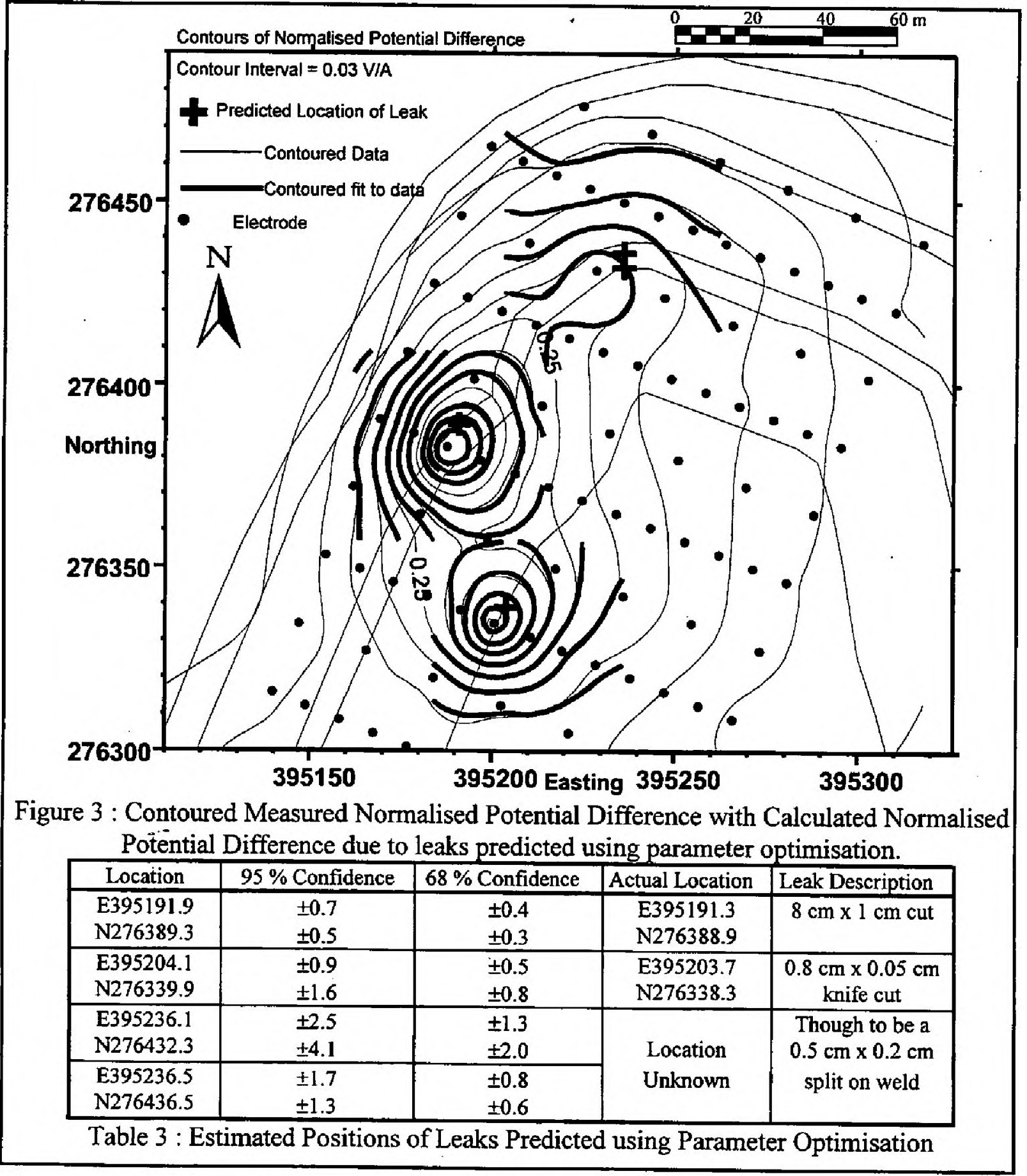

location test. By applying the parameter optimisation procedure to the data, the position of a leak can be predicted more accurately and thereby reduce the area of coverage and therefore 
time taken for the manual leak location test. An example of a set of contoured normalised potential difference data collected using the sub-liner grid is presented in Figure 3.

The contoured distribution of normalised potential difference calculated for the leaks predicted by the optimised fitting to the measured data is overlain in bold contours and shows a similar distribution to the real data. This suggests that the predicted leaks are real and there estimated positions are reliable. The predicted and actual leak positions are given in Table 3. It is clear that there is very good agreement between the predicted leak locations and the true locations, underlining the effectiveness of this procedure for the accurate location of leaks.

\section{TEMPORAL CHANGES IN THE SUBSURFACE}

Regular monitoring of the subsurface resistivity distribution has been conducted following installation of the geomembrane liner and a number of changes in the background resistivity distribution have been observed in both two-dimensional image sections and areal maps. Near surface changes are thought to be related to vertical migration of residual waters in the vadose zone toward the saturated zone. Measured decreases in the resistivity near to the top of the saturated zone are thought to be related to increases in the groundwater conductivity. Characterisation of the vadose zone below the liner from these results is currently underway.

\section{CONCLUSION}

The below-liner geophysical monitoring system has continued to prove its ability to detect leaks in the geomembrane with holes as small as $0.5 \mathrm{~mm}$ in diameter being detected. To improve the accuracy with which leaks can be located from the measured data, a parameter optimisation procedure has been employed. With such techniques, leaks can be located to an accuracy of $2 \mathrm{~m}$ or better, requiring only a short manual leak location survey to pin-point the source of the leak for subsequent repair. The detection and accurate location of even the smallest leaks attests to the sensitivity of the system and the effectiveness of the optimisation procedure. Further monitoring of the liner integrity and long term monitoring of temporal variations of the subsurface resistivity distribution will continue well beyond the life of the site.

\section{REFERENCES}

Frangos, W., 1994. Electrical Detection and Monitoring of Leaks in Lined Waste Disposal Ponds. SAGEEP '94 - Proceedings, Boston, USA.

Parra, J.O., 1988. Electrical Response of a Leak in a Geomembrane Liner. Geophysics Vol. 53, p1445-1452.

Taylor, S. B., Barker, R. D. and White, C. C., 1996. The UK's First Landfill Below-Liner Monitoring System : The First Year of Monitoring. EEGS '96 - Proceedings of the Second Meeting, Nantes, France.

Van, G. P., Park, S. K. and Hamilton, P., 1991. Monitoring Leaks From Storage Ponds Using Resistivity Methods. Geophysics, Vol. 56, p1267-1270.

White, C. C., Barker, R. D. and Taylor, S. B., 1996. Geophysical Leak Detection Systems for Landfill Liners : A Case History. Polluted and Marginal Land ' 96 - Proceedings of the Fourth International Conference, London, UK.

\section{ACKNOWLEDGEMENT}

The authors would like to thank Cleanaway Ltd for permission to present these results. 